\title{
Analysis of the Impact of Social Media on the Economy
}

\author{
Zheyu Cui ${ }^{1, a}$ \\ ${ }^{1}$ Finance, Rutgers University Business School, New Brunswick, 08901, NJ, USA. \\ ${ }^{a * C o r r e s p o n d i n g ~ a u t h o r . ~ E m a i l: ~ z c 209 @ s c a r l e t m a i l . r u t g e r s . e d u ~}$
}

\begin{abstract}
The article is an analysis of the impact of social media on the economy, and mostly how it helps the economy to grow. This article uses theory and data to demonstrate and analyze, and uses TikTok as an example to conduct research. The purpose of the essay is to demonstrate how social media can affect the economy in different ways geographically with the help of algorism, and how algorithms work effectively with social media. The author found that social media has increased opportunities for long-distance business and may increase domestic GDP levels. Social media opens up a new way of living and doing business, and it will continue to develop in the future.
\end{abstract}

Keywords: Economic Growth, TikTok, Social Media, Online market.

\section{INTRODUCTION}

With more population using new technology inventions, young generations started to forget about the old entertainment, and let Social media step into their lives. As a Gen Z, most of my generation grew up with technology renovations and became the expert on modern laptops and cellphones. We spend most of our time surfing online, which gives social media the power to create more value. The early social media targeted users' to keep personal contact, it later transformed into big data that could be used for almost everything. Social media is a network with a large amount of information flow. Through social media platforms, people can promote products to appropriate audiences. The frequent and widespread use of social media can represent the economic status of a region or a country. The greater the user density, the wealthier the place, and vice versa. Social media allows users to share their information with others, where people are more connected than before because of the large number of users on social media. Social media's ongoing popularity and frequent updates allow businesses to target more potential consumers and raise regional or domestic GDP by exploring the social media market. The geographic difference makes the effectiveness of using social media various, which creates unique targets for marketers and increases travel [1]. It is the same that different social media platforms can affect economic growth differently. Social media is a game-changer that opens a new lifestyle and a unique market for users to try. The paper will use theoretical research to demonstrate, and let more people understand and value the potential and contribution of social media to the economy. This article will further explore the impact of social media on economic growth and how marketers can use social media to increase purchasing power. Also, the author discusses the potential market social media can expand in the future for economic development.

\section{THE IMPACT OF SOCIAL MEDIA MARKETING}

\subsection{The development of social media}

The market generated by modern social media is called the new media era, such as YouTube, TikTok, and Facebook, while traditional media are platforms like newspapers, TVs. The essay is more inclined to the influence of new media on economic development as the research object. Comparing the new media era and the traditional media era, they have different ways of marketing. The traditional media pays more attention to the channels of information dissemination, and the filtering and screening of information are very limited. The main dissemination method is also very one-sided, commercial information will appear very monotonous, and the information that readers see is basically the same. Traditional media allows readers to find the information they want, while new media allows information to spread to every potential reader's screen. New media values individuals and spreads quickly. It selects the desired information for the social media user contest and usually displays relevant content with high 
user attention and participation. Social media provides users with a private platform, and users can also share what they see. In this way, each individual uses his potential as a medium for information dissemination. The lower cost of social media achieves sustainable communication and reduces the distance between consumers, so as to better understand consumers and lay a solid foundation for long-term marketing.

Before the existence of social media, marketers needed more effort to put out their businesses information that doing business long-distance is quite impossible. Without social media, businesses need more labor resources to spread their products or services to others. While, with the existence of social media, it is much easier for merchants to do business. They can establish their official business social media accounts on major social media platforms, which reduces many barriers for them to find potential consumers around the world. They can improve sales by using the "like economy" [3] that can represent their popularity to the public. It is also more beneficial and profitable for smaller brands or businesses that have limited funds and resources, which promotes the development and growth of the economy. From the data, $91 \%$ of retailers opened up at least two social platforms, which means the emergence of diversified businesses can open up practical vacant markets. This allows successful small businesses to add new positions to the regional employment market, which also means that unemployment rates will fall and productivity will rise. Society is also more stable, and the economy will continue to develop. Social media opens the potential market for every user they have and presents the product or service directly to potential buyers.

The accuracy of the promotion depends on the use of the algorithm. The algorithm is a process of calculation that operates in a computer that can analyze the data. Social media take the advantage of the algorithm to analyze their users' interests and behavior on their servers so that they can extract the right or potential content to their users. In other words, the algorithm increases the exposure of useful information and tailors promotional information for social media users. It affects the sales and production of the promoted products and services that some social networks are capable of reaching out to billions of users. Sometimes the potential buyers or existing ones just need more encouragement to make their orders. It is up to the merchants how they want their audiences to engage in the content they created in their social networks. When potential customers learn about new products or services, sales and productivity will rise. In the long run,
GDP would increase with the surge in public purchasing power and demand.

Nowadays, social media has penetrated widely into the social life of users. The addition of algorithms has improved the quality of information dissemination [4], greatly improved the user experience, and met the diversified needs of consumers. It has opened up a new, convenient, and cost-effective marketing method, and has been valued by large and small enterprises. Even some social platforms have become the most important part of some businesses and corporate marketing. The circulation of information has also promoted the universality of online transactions. In China, you can complete all consumer payments as long as you bring your mobile phone when you go out. In this case, it opens up a new way for money exchange that improves consumer demands and increases sales' availabilities. In addition, social media also brings unknowing risks to users. Most social media acquire users' private information for information dissemination accuracy, and it makes users' lives relatively transparent to strangers or friends [2], but most social media will protect users' personal information. Social media gathered a lot of personal data and business information, bringing life into the era of "big data". "Big data" as an information database has established a valuable start for later analysis, research, and prediction of future economic development. Therefore, social media currently has a long-term development space, and it also has challenges in terms of security and privacy.

\subsection{The impact of urbanization on the use of social media}

When analyzing the demographics of social media, the author notices that the more urbanized area has more people using social media. As shown in figure (1) below of the \% U.S adults who say they use at least one social media site, by community type; $76 \%$ of people use at least one social media site in the urban area, $71 \%$ in the suburban area, and $66 \%$ in the rural area since Feb 8 , 2021. It is a lot less from the early years. The population density in urban areas is greater, the economy will be more developed and improved, and more people will use social media. Suburban areas and rural areas are relatively sparsely populated, and the population density is lower than urban areas. If a region's use of social media in suburban areas and rural areas is closer to the use of social media in the city, then the economy of the region will be more developed than the economy of other places where the gap between urban, suburban, and rural is larger. 


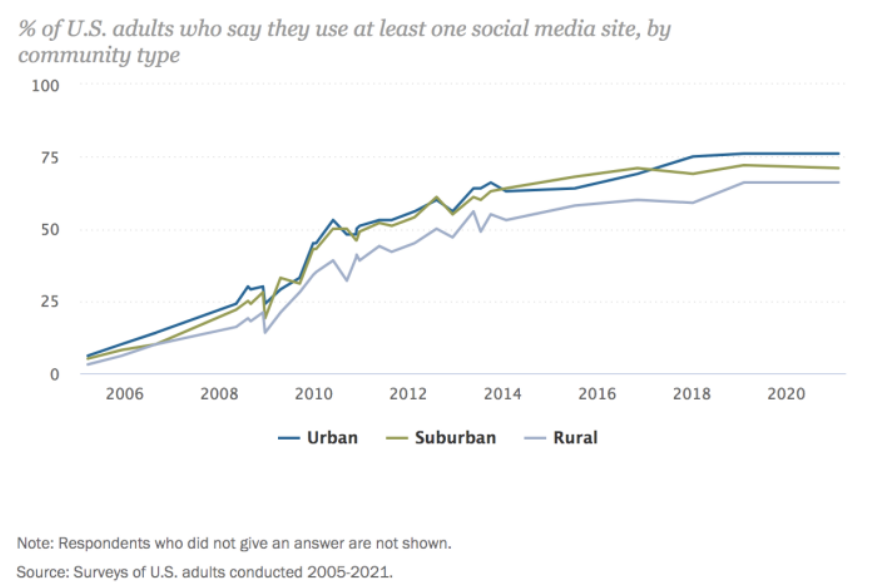

Figure $1 \%$ U.S adults who say they use at least one social media site, by community type[7]

When farmers in rural areas use social media to spread their agricultural products, more people living in cities will learn about their agricultural products. Compared with selling to resellers, farmers will benefit more from buying agricultural products independently, and consumers who purchase can also better understand the detailed information of the products they buy. In this way, the farmer and his consumers can build trust and make the process from production to purchase to sale more transparent. When the sales of agricultural products in rural areas increase, farmers will have a stable source of income. They will increase production to meet customers' demands, and at the same time positively affect the regional GDP. The economy of rural areas will be improved, and facilities will be updated. When the use of social media in these three regions rises and areTikTok close to each other, the three regions will gradually combine to a more popularized urban area. The dense population brings large consumption power and is followed by a market that spreads and proliferated through social media.
Most of the people who use social media frequently belong to middle or high-income households, and most of them gather in urban areas. As shown in Figure (2) of the \% U.S adult who says they use at least one social media site, by annual household income, there are $78 \%$ in the $\$ 75,000+$ annual income household, $76 \%$ in the $\$ 30,000$ - \$49,999 annual income household, $69 \%$ in the less than \$30,000 annual income household, and 65\% in the $\$ 50,000$ - $\$ 74,999$ annual income household since Feb 8, 2021. Besides the decrease from Feb 7, 2019 Feb 8, 2021, in the $\$ 50,000$ - \$74,999 annual income household, other households' data shows an increase in social media use as the income increases. Comparing low-income families with high-income families, highincome families have more purchasing power. As more high-income households use social media, their consumption levels will also rise, which stimulates market change.

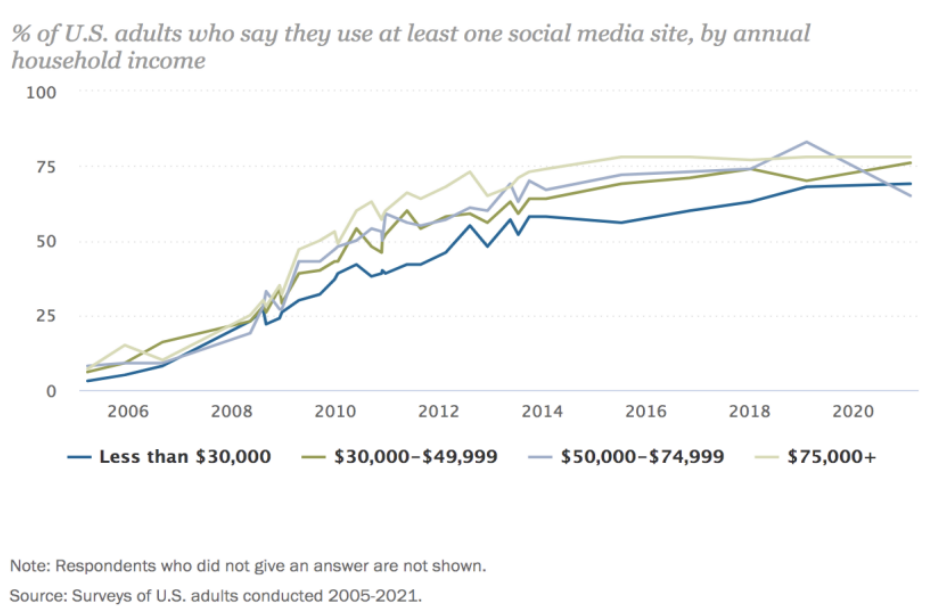

Figure $2 \%$ U.S adult who says they use at least one social media site, by annual household income [7] 


\section{TAKE TIKTOK AS AN EXAMPLE TO ANALYZE ONLINE MARKETING}

TikTok, a video-based app that allows you to create videos and share them directly with friends or the public, is well known for its unique video editing features, and users are regardless of young or older generation.

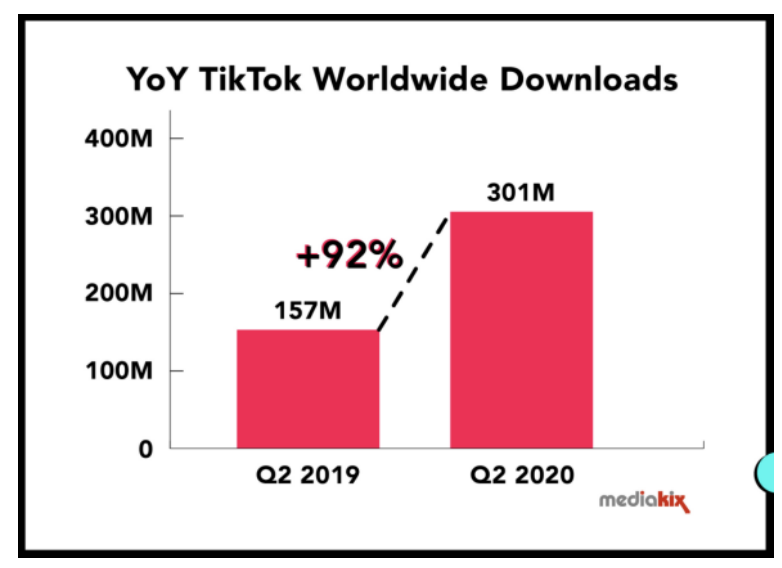

Figure 3 "TikTok Worldwide Downloads[5]

Since TikTok has such huge users and audience growth from observing Figure (3) of TikTok worldwide downloads above, many brands and businesses want to corporate. Some small businesses and brands' products blew up because of TikTok. Advertising on TikTok is more convenient and less costly than other traditional ones, like commercials on TVs or posters. It saves a reasonable amount of marketing financial investment. In order to have a successful promotion of a product or service on TikTok, businesses should focus more on creating and following trendy videos on TikTok. Businesses creating amusing content to attract potential buyers is more important because it can get viral that can expose millions of viewers based on the observation of the TikTok user growth from 2019-2020. Outstanding content also wins your business a competitive advantage over other similar brands because it allows you to stand out from the competitors and make adjustments by getting in touch with the consumers. While TikTok supports new and old businesses to expand their market to potential buyers, it creates new jobs that reduce the unemployment rate. As one of the world's leading social networking sites, TikTok needs various manpower and material resources to maintain. As it continues to increase in the number of users, it will continue to recruit talents to manage and maintain development in the later stages.

\begin{tabular}{|c|c|c|c|}
\hline Rank & TikTok username & Followers & Estimated earnings per post \\
\hline 1 & charlidamelio & $45,900,000$ & $\$ 73,510$ (US $\$ 45,863$ ) \\
\hline 2 & lorengray & $42,000,000$ & $\$ 67,275$ (US $\$ 41,973$ ) \\
\hline 3 & zachking & $39,600,000$ & $\$ 63,622$ (US $\$ 39,694)$ \\
\hline 4 & riyaz.14 & $34,200,000$ & $\$ 54,986$ (US $\$ 34,306)$ \\
\hline 5 & babyariel & $31,900,000$ & $\$ 51,065$ (US $\$ 31,860)$ \\
\hline 6 & addisonre & $31,200,000$ & $\$ 50,028$ (US $\$ 31,213$ ) \\
\hline 7 & spencerx & $27,100,000$ & $\$ 43,534$ (US $\$ 27,161$ ) \\
\hline 8 & gilmhercroes & $25,600,000$ & $\$ 41,070$ (US $\$ 25,624)$ \\
\hline 9 & _arishfakhan_ & $24,100,000$ & $\$ 38,587$ (US $\$ 24,075$ ) \\
\hline 10 & kristenhancher & $23,600,000$ & $\$ 37,829$ (US $\$ 23,602$ ) \\
\hline
\end{tabular}

Figure 4 TikTokers estimated earning per post[6]

TikTok has also opened up the short video market. Users who make videos can earn endorsements and promotion fees for cooperative products or services by sharing short videos. The above figure (4) TikTokers estimated earning per post, shows the top TikTok creators estimated income of sharing one post of a short video, which shows that TikTok is not only used for entertainment but also the users can earn money from brand promotions. It creates potential career choices for young adults and opens up a new buying habit for consumers on social media. 


\section{CONCLUSION}

The power of social media cannot be ignored, especially in terms of economic development and expansion. It also has many hidden values that will be revealed in the long development of the world economy. The current economic performance is indispensable to the advancement of social media. With the emergence of social media platforms, there is no fear of finding potential buyers. The emergence of social media platforms has reduced the cost of small businesses, while at the same time it has improved the opportunities to find potential buyers and established an open market. It makes the market transparent, allows consumers to build trust in the products they use, and allows them to learn more about products or services. Different brands have established brand homepages on social media to gather loyal users, and can also update after-sales at any time, which improves product quality and user satisfaction. High-quality and convenient after-sales is essential to the sale of products, it can improve the market demand and supply of products or services. Social media has opened up various aspects of information dissemination and opened up potential financial markets. The algorithm allows social media to provide users with a tailor-made information network, which improves the delivery of effective information [4]. The differences in the use of social media in different regions have also opened up the potential growth and expansion of the market in the future. It makes it feasible to open up the economy of remote areas and expand the products and purchasing power of remote areas to all parts of the world. Innovative marketing and entertainment that does not disturb consumers also satisfy the delivery of information. The research of the article is a unilateral analysis, and the influence of social media is only one of the factors of economic development. There are many different aspects that promote economic development, such as the signing of policies, cultural differences. Social media has a profound impact on the modern economy, and it will continue to influence and make greater contributions to economic development in the future. The article serves as a reference to understand the current development trend of social media and hopes that more people will pay attention to and correctly use the influence of social media on economic emergence.

\section{ACKNOWLEDGMENT}

I cannot express enough deep and sincere gratitude for those who continued their supports and guidelines throughout the completion of my essay. Firstly, I would like to show my deepest gratitude to my teachers and professors, who have provided me with valuable guidance in every stage of the writing of this thesis. Further, I would like to thank all my friends and parents for their encouragement and support to allow me to finish the essay. Without all their enlightening instruction and impressive kindness, I could not have completed my thesis.

\section{REFERENCES}

[1] Huerta-Álvarez, Rocío, Jesús J. Cambra-Fierro, and Maria Fuentes-Blasco. "The interplay between social media communication, brand equity and brand engagement in tourist destinations: An analysis in an emerging economy." Journal of Destination Marketing \& Management 16 (2020): 100413.

[2] Leonardi, Paul M. "Social media, knowledge sharing, and innovation: Toward a theory of communication visibility." Information systems research 25.4 (2014): 796-816.

[3] Gerlitz, Carolin, and Anne Helmond. "The like economy: Social buttons and the data-intensive web." New media \& society 15.8 (2013): 13481365.f

[4] Yang, Jeremy, Juanjuan Zhang, and Yuhan Zhang. "INFLUENCER VIDEO ADVERTISING IN TIKTOK."

[5] Figure (3) from MediaKix, 2020, TIKTOK USER GROWTH INFOGRAPHIC - 2020 DATA + CHARTS, Retrieved August 6th, 2021, https://mediakix.com/blog/tik-tok-user-growthinfographic/\#: :text=TikTok\%20user\%20growth\% 20 is $\% 20$ fueled $\% 20$ by $\% 20$ its $\% 20$ downloads $\% 2$,t o\%20Q1\%20and\%20Q2\%20of\%202019\%20\%283 $43 \% 20$ million $\% 29$.

[6] Figure (4) from Pedestrian, Vanna O’Brien, 2021, Here's Exactly How Much The Top TikTokers Get Paid \& Yep, Should Have Kept Up Dance Lessons, Retrieved August 6th, 2021, https://www.pedestrian.tv/online/tik-tok-earnings/

[7] Figure (1) and (2) from the pew research center, 2021, Social Media Fact Sheet, Retrieved August 6th, 2021, https://www.pewresearch.org/internet/factsheet/social-media/?menuItem $=4$ abfc543-4bd1 4b1f-bd4a-e7c67728ab76 